\title{
ALÉM DO CONSENSO DE WASHINGTON: "REFLEXÕES" SOBRE EQÜIDADE, DEMOCRACIA E CONFLITO NA AMÉRICA LATINA
}

\author{
Mark L. Schneider
}

\begin{abstract}
Resumo
O Consenso de Washington fracassou em vários dos seus objetivos, na medida em que se tornou cego para a importância de governança e o papel do Estado. Sem uma governança inclusiva, efetiva e que preste contas, não somente será mais difícil de implementar reformas macro e micro-econômicas mas, sua implementação deficiente mina a sustentabilidade dessas reformas. Inevitavelmente algumas das medidas produzem perdedores e vencedores e, os pobres e mais vulneráveis sempre são os mais propensos a ser perdedores. Quando as medidas foram implementadas de forma corrupta, ou percebidas dessa maneira, as conseqüências exacerbam o sentido da exclusão e alienação de segmentos crescentes da população. Não é como se não soubéssemos formas de incorporar os pobres na vida nacional: acesso à terra via reforma agrária, investimentos em facilidades de micro e pequeno crédito, tecnologia e infra-estrutura rural e investimento em capital social. Estas medidas fortaleceriam a inclusão da população rural, aumentariam a coesão social e, suspeito eu, que fortaleceriam as instituições democráticas. Esse apoio é necessário para superar o senso de impunidade que estimula as elites a não pagar impostos, a tratar os empregados com dignidade e a recusar acesso privilegiado a contratos e pagamentos à margem da lei. A crença de que aqueles com poder são impunes perante a lei mina o ethos democrático. Viola o contrato social.
\end{abstract}

Palavras-Chaves: Governaça; Taxação; Corrupção.

\begin{abstract}
The Washington Consensus failed in the full range of its objectives, because it was relatively blind to the importance of governance and the role of the state. Without effective, inclusive and accountable governance, not only was it more difficult to implement the macro and microeconomic reforms but the flawed implementation undermined the sustainability of those reforms. Inevitably some of the measures produced losers as well as winners, and the poor and the most vulnerable always tended to be the losers. When the measures were implemented corruptly, or perceived as such, the consequences exacerbated a sense of exclusion and alienation of growing segments of the population. It is not as if we do not know ways to incorporate the poor in national life: access to land through land reform; investment in micro and small credit facilities; technology and rural infrastructure; investment in social capital. All of these measures would enhance the inclusion of the rural population, increase social cohesion and I suspect strengthen support for democratic institutions. Such support is necessary to overcome the sense of impunity that persuades many in the region that the elites in their countries fail to pay their taxes, fail to treat their employs with dignity, receive favored access to contracts and pay their way out of any brush with the law. The belief that those with power have impunity from the fair
\end{abstract}


enforcement of the law undercuts the democratic ethos. It violates the social contract.

Key-Words: Governance; Taxation; Corruption.

\section{Introdução}

Respeito aos direitos humanos, promovendo justiça social, fortalecendo a democracia e reconhecendo que o desenvolvimento deve ser construído com a prioridade de reduzir a pobreza e diminuir as diferenças: esta é a estrutura política que ainda creio ser do interesse da América Latina e dos Estados Unidos. O desenvolvimento é absolutamente necessário, mas está longe do que se considera suficiente, e a incapacidade de enfrentar a pobreza e a desigualdade inevitavelmente age como um entrave ao crescimento. Esta é uma razão de por que o Consenso de Washington estava mal encaminhado desde o início.

O Consenso de Washington não teve sucesso em seus objetivos por outra razão. Ele, de certa forma, ignorou a importância da governança e do papel do Estado. Sem uma governança de inclusão eficaz e reconhecida, não só era mais difícil implantar as reformas macro e microeconômica, como também uma implementação mal conduzida minava a sustentabilidade daquelas reformas. Inevitavelmente, algumas dessas medidas produziram resultados positivos e negativos, e os pobres e mais vulneráveis sempre foram prejudicados.

Quando as medidas foram implantadas de forma corrupta, ou percebidas como tal, as conseqüências exacerbaram um sentido de exclusão e alienação de crescentes segmentos da população. Muita coisa foi cumprida na década passada, quando se abriram novas escolas e clínicas, reduzindo o nível de mortalidade infantil, que era de 100 por 1000, uma em 10, em 1980, para 25 em 1000, uma em 40, e elevando, assim, a expectativa de vida significativamente.

O acesso à educação primária aumentou, mas as lacunas em termos de justiça social permanecem longe do ideal, dados os níveis de rendimento disponíveis para os países da América. Apenas mais um exemplo com relação à mortalidade infantil: mesmo com uma situação 
bem melhor, a diferença entre a América Latina e os países da Organisation for Economic Co-operation and Development (OCDE), aumentou entre 1980 e 2006.

Em 1980, havia 3 vezes mais probabilidade de um recém-nascido morrer antes de completar seu primeiro ano de vida na América Latina, e agora, provavelmente, a chance é 6 vezes maior. Há uma década, no $50^{\circ}$ aniversário da Organização dos Estados americanos (OEA), Carlos Fuentes 1998 disse: "O clamor da América Latina é: queremos democracia política, desenvolvimento econômico e justiça social. Nós queremos todos eles juntos. E os queremos agora." Ele disse que a América Latina estava num momento ímpar. Pela primeira vez em sua lembrança, os hemisférios norte e sul compartilhavam a mesma percepção da importância da democracia política, do desenvolvimento econômico e da justiça social, e de como alcançar essas metas.

Eu duvido que ele falaria o mesmo hoje. A importância daquelas metas permanece a mesma. Mas não existe mais consenso de "como chegar lá". O Consenso de Washington tem-se tornado contensioso, e há uma percepção disseminadora de discriminação e injustiça no modelo econômico dominante.

\section{Consenso}

O Consenso de Washington consistia em um plano de 10 pontos, elaborado por John Williamson, em 1990. De acordo com o autor, o plano não era uma receita inovadora ou única para um desenvolvimento completo, mas antes, sua melhor dedução de um mínimo denominador comum das políticas econômicas dos principais parceiros econômicos em Washington, DC, com esperança de ajudar a América Latina a sair da "Década Perdida" dos anos 1980.

A meta, como ele declarou, era "acelerar o crescimento sem piorar a distribuição de renda". Seu plano de 10 pontos girava em torno de três grandes idéias: disciplina macroeconômica, economia de mercado e uma política de abertura tanto para o comércio internacional quanto para investimentos estrangeiros diretos, sendo todas as três apoiadas pelo Tesouro Americano, pelo Banco Interamericano de Desenvolvimento 
(BID), pelo Fundo Monetário Internacional (FMI) e pelo Banco Mundial, no começo da década.

Para os países menores das Américas, nos anos 1990, particularmente para aqueles que dependiam de políticas de empréstimos e condições colocadas pelas Instituições Financeiras Internacionais (IFIsinternational financial institutions), o Consenso de Washington era bem claro. Era a lei da macroeconomia. Alguns dos formuladores de política da administração Bill Clinton pressionavam por mudanças naquela matriz política. Enquanto algumas das reformas das dez metas tinham méritos claros, outras só seriam positivas se complementadas por governanças efetivas, instituições reconhecidamente democráticas que buscavam a inclusão, bem como uma estrutura política que desse igual atenção e prioridade ao investimento em capital humano e redução da pobreza.

Eu suspeito que poucos reconheceriam que entre os dez itens da agenda estariam a reforma fiscal e o foco em gastos públicos, como Nancy Birsall observou no Consenso de Washington, "com alto retorno econômico e um potencial para aperfeiçoar a distribuição de renda". Por não se focar na governança, em seu papel de realizar aqueles objetivos, e pela falta de atenção sobre esses últimos por parte dos doadores, muitos simplesmente os ignoraram, e por não ter sido dada prioridade à redução da desigualdade, o seu "potencial" era, em grande medida, retórico. Quanto a impostos, o Center for Global Development e o Inter-American Dialogue observaram que, na maioria dos países da América Latina, aberturas e evasão eram a norma.

O relatório do Banco Mundial sobre desigualdade na América Latina acrescentou que, a despeito de sistemas fiscais de amplo acesso a serviços, deve acabar o que se chama de "Estado de bem estar elitista e truncado" da América Latina, para que a previdência social chegue aos pobres. Mesmo avaliados pelo coeficiente de Gini, ou outros índices, os países latino-americanos não têm tido políticas efetivas de inclusão e distribuição de renda, que revertam as disparidades de renda e poder nessas sociedades.

O regime de impostos latino-americano tem mostrado um total baixo e baixas taxas limitadas, tarifas inapropriadas, prevalência de 
impostos de isenção, capacidade administrativa insuficiente, e o mais importante, fracos efeitos de distribuição de renda, focados em grande parte em impostos sobre o alto consumo. Para aumentar suas próprias receitas e financiar projetos sociais, visando à redução da desigualdade, os governantes latino-americanos devem estar dispostos a praticar uma maior taxação sobre rendimentos e riquezas. Impostos sobre rendimentos e lucros, que proporcionam maior redistribuição (da riqueza), representam uma pequena proporção da receita total na América Latina. Em 2001, a média regional era de $5 \%$ do PIB, comparado aos $6,5 \%$ para outros países com economias de mercado emergentes e $12,5 \%$ para a Organização para a Cooperação e Desenvolvimento Econômico (OCDE ou OECD em inglês). As reformas fiscais desenvolvidas nos anos 90, sobre o estandarte do Consenso de Washington, impactaram pouco em relação a estes pontos, porque eles nunca estavam no topo da agenda de política bilateral ou multilateral.

Para refrear os problemas de desigualdade discutidos acima, um maior número de políticas fiscais visando a uma melhor redistribuição da riqueza deveriam ser vigorosamente buscadas em toda a região. Aqui novamente, não é a discordância sobre as metas, mas, o fato de não haver um consenso político "sobre como chegar lá" e como construir políticas de coalizão que conduzam a tais reformas com liberdade.

Vale a pena lembrar onde o hemisfério estava no final da "década perdida" do desenvolvimento, os anos 80 . O nível médio de inflação na região era de 450\% entre 1986 e 1990. Até 2000, o nível médio de inflação havia caído para $10 \%$. Além disso, por meio do aprimoramento do controle fiscal nos anos 90, a média do déficit orçamentário da região baixou mais da metade (de $5 \%$ para $2 \%$ do GDP) e a dívida externa reduziu de $50 \%$ para $20 \%$ do GDP.

Mesmo aqueles que apoiavam o Consenso de Washington tiveram que admitir que ele não teve êxito em estimular o crescimento econômico em níveis semelhantes aos da Ásia. O prometido trickle-down, impacto sobre a pobreza e a desigualdade, nunca alcançou os pobres e os excluídos. Nem as suas políticas alcançaram os prometidos níveis capazes de acelerar o crescimento. 


\section{O Crescimento do PIB Latino-Americano}

De 1988 até 2006, a mudança na média anual em porcentagem no GDP para a América Latina foi de 3,2\%, consideravelmente mais baixo que a média do Oriente Médio, 4,3\%, e menos da metade dos $7,6 \%$ da Ásia no mesmo período. Além disso, grande parte do desenvolvimento mais significativo da América Latina ocorreu nos últimos quatro anos, mas a mudança de 5,3\% no GDP desde 2003 ainda está abaixo do Oriente Médio, de 5,6\%, e longe do desenvolvimento da Ásia, de 9\% desde 2002.

A taxa de crescimento latino-americano também é de certa forma distorcida pelo grande crescimento das ricas economias do petróleo. Então, pode-se argumentar que até a causa impulsora básica de apoio ao Consenso de Washington - a busca de maior crescimento econômico não se realizou. Enquanto Williamson argumenta que, uma vez que sua agenda de dez metas não foi completamente implementada, ela não

deveria ser culpada pelos baixos níveis de crescimento e, conseqüentemente, pelo mínimo impacto sobre a pobreza e a desigualdade.

A natureza mínima do impacto sobre a pobreza e a desigualdade demanda sérias revisões da agenda original. Williamson declarou que enquanto muitas reformas que ele promoveu beneficiaram os pobres e marginalizados indiretamente, ele especificamente omitiu algumas estratégias que eram estritamente de natureza distributiva, acreditando ser "a Washington dos anos 80 uma cidade indiferente aos propósitos de igualdade". Receio que a retórica possa ser diferente, pois as políticas do governo dos EUA, nos últimos sete anos, não demonstraram dar maior atenção àqueles problemas da região ou mesmo do próprio país.

\section{Pobreza}

De acordo com a Comissão Econômica Especial para a América Latina e o Caribe (CEPAL), desde 1990, a pobreza na região tem sido reduzida para um pouco menos de $10 \%$. Porém, em 2006, 38,7\% das pessoas da região ainda estavam vivendo abaixo da linha de pobreza, e cerca de $15 \%$ estavam classificadas como extremamente pobres ou 
indigentes. Em termos absolutos, a população que vive na pobreza atualmente cresce aproximadamente 5 milhões no mesmo período. Além disso, desde 1980 o número de pessoas na América Latina que vive em extrema pobreza aumentou de 62 milhões para 79 milhões. A população total que vive na pobreza passou de 136 milhões em 1980 para 205 milhões no último ano.

Se olharmos particularmente para a área rural da América, a pobreza ainda ronda os 70\%. O Banco Mundial constatou que pelo menos em 12 países, a maioria dos pobres encontra-se na área rural.

\section{Injustiça e desigualdade}

Desde sua colonização, a desigualdade econômica e social tem caracterizado a história da América Latina, atuando como um obstáculo na capacidade de crescimento da região. A desigualdade existe em todo o planeta, mas é muito pior na América Latina.

De acordo com o Relatório sobre Desenvolvimento Humano (UNDP), $10 \%$ da população mais rica da região recebe $48 \%$ da renda nacional, enquanto os $10 \%$ mais pobres recebem 1,6\%. Também é sabido que os $10 \%$ mais ricos virtualmente não pagam impostos. Talvez a impressionante estatística, vinda do World Book da CIA foi a de que dos 98 países avaliados, sobre os quais esses dados estavam disponíveis, 12 dos 20 onde há mais desigualdade no mundo estavam na América Latina. Como exemplo específico latino-americano, o Crisis Group informou que em 2005 , os $10 \%$ mais ricos da Bolívia possuíam uma renda 140 vezes maior do que os $10 \%$ mais pobres.

Outra medida da distribuição de renda é dada por meio de análises da pobreza relativa, a qual é mais freqüentemente avaliada por calcular a porcentagem de uma população que está "sob o risco de tornar-se pobre, tendo como base um patamar equivalente a $60 \%$ do equivalente nacional médio da renda disponível". No final da década perdida dos anos 1980, a média da pobreza relativa era de cerca de $27,5 \%$. Depois de nove anos de reformas misturadas pelo Consenso, a taxa alterou-se muito pouco, com um percentual de 28,6\%, e ainda chegaria a $27,7 \%$ em 2005 . O que talvez seja a pior média do coeficiente de GINI - talvez a melhor 
medida objetiva de desigualdade na distribuição de renda - para a região, teve um aumento real de 0,55 em 1990 para 0,58 em 1999.

As elites, caracteristicamente políticas e econômicas, têm controle suficiente sobre o poder de proteger seus interesses, e por meio desse processo, produziram essas distorções na distribuição de renda que, por sua vez, geram polarização e exclusão.

\section{Discriminação}

Um fenômeno ligado ao desafio da redução da pobreza e da injustiça é o crescente entendimento de que os povos indígenas e afrolatino-americanos ainda são continuamente discriminados. Os estudos do Banco Mundial evidenciaram indígenas do sexo masculino ganhando $65 \%$ menos do que homens brancos em sete países que possuíam predominância de indígenas entre a sua população. As mulheres indígenas também têm menos acesso à água potável, educação e emprego. Apesar de muitos países latino-americanos terem promulgado leis proibindo atos racistas e estabelecido ministérios para proteger os direitos dos grupos indígenas, eles permanecem entre os mais vulneráveis no hemisfério.

O fracasso dos governos democráticos em sua prioridade de diminuir a exclusão desses grupos, principalmente dos que vivem nas áreas rurais de seus países, tem gerado medidas paralelas, aumentado a violência e criando instabilidade política. Essa é a razão pela qual o International Crisis Group tem dado mais atenção a estes problemas que potencialmente podem conduzir para a instabilidade e a violência. O relativo fracasso quanto à melhora da infra-estrutura física das estradas, abastecimento de água, eletricidade e saneamento, bem como de escolas e hospitais para suas comunidades, se reflete na contínua ausência de coesão social em muitos países da região. Esta ausência de coesão social, como argumentou a CEPAL, prejudica o sentimento de pertencimento, que é a antítese da inclusão "fundamentada sob o efetivo exercício da cidadania e da ética democrática".

O International Crisis Group também ignora o sucesso da experiência do Sudeste asiático onde havia um relativo equilíbrio nos 
investimentos na infraestrutura urbana e rural e uma subseqüente igualdade relativa entre aquelas áreas.

\section{Democracia}

O Consenso de Washington silenciou quanto às mudanças políticas ocorridas no hemisfério com o declínio de regimes militares e o fim da Guerra Fria. Entretanto, muitos estavam adormecidos na década passada, pensando que todos aqueles países estavam avançando ao longo de um caminho comum em direção a valores democráticos e crescimento com igualdade em comum acordo sobre quais políticas eles percorreriam. Esta confiança desmantelou-se pelo próprio fracasso do Consenso quanto a alcançar seus objetivos. Mas esse insucesso estava intimamente envolvido com problemas na transição democrática.

Nós todos conhecemos os panoramas: doze presidentes não terminaram seus mandatos desde 1990; e desde 2000, três presidentes foram destituídos somente no Equador, dois presidentes destituídos do cargo na Bolívia e um no Haiti. Legítimas frustrações para cujos países as reformas econômicas não ofereceram nenhuma melhora visível ou suficiente na vida de seus cidadãos ou expectativa de seus descendentes, tendo acarretado populismo e minado o sistema econômico, que nada produziu para eles. A reforma eleitoral de forma pragmática, porém não ideológica, proporcionou um chamamento sobre como atingir resultados por meio de iniciativas individuais ou de movimentos cujos objetivos são menos claros, a fim de capitalizar sobre aquela frustração e assegurar o controle do Estado.

Durante a década passada, o crescimento da instabilidade política, bem como da potencialidade para a violência, pode ser visto na Venezuela, Bolívia, Equador, Peru e agora na Guatemala, bem como no Haiti. Há muitas razões para o surgimento dessas condições em cada um desses países.

Mas há alguns elementos semelhantes que remetem à discussão que estamos fazendo sobre o Consenso de Washington, os problemas relacionados à pobreza, à injustiça, à discriminação, e à falta de coesão social. O International Crisis Group, uma organização sem fins lucrativos, 
tem examinado as causas dos conflitos nos Andes e no Haiti, e nesses estudos fica cada vez mais claro que esses problemas abrem caminho para a instabilidade política e a violência excessiva. Em cada um destes países, as populações rurais foram em grande parte excluídas da economia nacional e dos principais objetivos políticos. Isso tornou mais difíceis outras metas regionais e nacionais. Na Colômbia, torna-se mais difícil dar fim a um conflito cujas vítimas são, em sua maioria, a população rural não combatente (civil).

O International Crisis Group produziu um relatório sobre The Humanitarian Crisis in Colombia e de forma não surpreendente, concluiu que as áreas rurais com os maiores níveis de pobreza estavam nas regiões onde os conflitos eram mais severos. A maioria da população deslocada da sua habitação original Na Colômbia, que tinha o terceiro maior índice mundial, pertence às áreas rurais. Estamos convencidos de que independentemente do que ocorra de positivo na Colômbia, na ausência de uma estratégia de desenvolvimento rural visível e de alta prioridade, todos os esforços para trazer um fim permanente ao conflito se tornam muito mais difíceis. A mesma situação ocorre hoje em relação às conseqüências da desmobilização paramilitar.

Estive em populações rurais e encontrei ex-paras, suas vítimas nas comunidades rurais de Tierralta, e os desalojados, todos perguntando onde estavam os benefícios prometidos nas escolas, hospitais e empregos. Não é de se admirar a reaparição do armamento de grupos paramilitares.

Nos Andes como um todo, a pobreza desproporcional da população rural torna mais difícil confrontar a indústria de narcóticos que freqüentemente usa a intimidação, a força e a violência, para coagir camponeses a cultivar coca; mas também os paga bem para uma colheita fácil que pode ser plantada e colhida três vezes ao ano. No Peru, na Bolívia, no Equador e na Colômbia, os problemas estão relacionados à exclusão de populações indígenas da total participação na vida nacional.

Estão abaixo relacionadas medidas que aumentam a inclusão da população rural, elevam a coesão social e, eu acredito que fortalecem o 
apoio a instituições democráticas. Tudo depende de uma capacidade ativa de eficiência governamental.

- Na América Central isso permanece como uma promessa ainda não cumprida dos acordos de paz, esperança de acordos de paz, e pleitos não atendidos de transformação e não simplesmente reconstrução, em resposta ao Furacão Mitch. E eu suspeito que terá sido feita novamente no caso do Furacão Felix. Não é como se nós não conhecêssemos maneiras de incorporar os agricultores pobres na vida nacional;

- Investir na expansão do acesso de agricultores pobres à terra através de reforma agrária- de uma maneira ou de outra, isto é, através da venda de terras, fundos agrários e o que no Brasil se chama "venda de terras com a ajuda de reforma agrária", através da expropriação de terras improdutivas, ou através de mecanismos de taxação de terras que estimulem a disponibilização de terras a pequenos agricultores;

- Investir no fornecimento de títulos seguros para propriedades de agricultores pobres como um passo fundamental para capacitá-los a adquirir créditos de operação para administrar seus cultivos e micro e pequenos empréstimos para suas atividades não agrárias;

- Investimento adicional massivo em micro e pequeno crédito para equipamentos a fim de capacitar os sujeitos a usar sua terra mais produtivamente e facilitar suas atividades extra-agrárias. Enrique Iglesias foi a uma conferência sobre micro-financiamento e nós concluímos que a United States Agency for International development estava financiando perto de 1 milhão de microempresários e o BID, Banco Mundial e outros, outro 1 milhão - e a necessidade era de 50 milhões;

- Investimento em tecnologia e infra-estrutura rural - de modo que estradas rurais, eletricidade, água, esgoto e informação tecnológica realmente atinjam os agricultores pobres;

- Investimento em formação de capital humano - em escolas, saúde, nutrição;

- Investimento em capital social; cooperativas e joint ventures, micro-empreendimentos rurais.

Sobre a questão da corrupção, da impunidade e do frágil poder da lei, essa é outra razão porque o Consenso de Washington não teve êxito 
em produzir uma estrutura para um desenvolvimento mais igualitário, ou seja, que produzisse uma maior estabilidade reduzindo a possibilidade de conflito interno. A despeito da adoção da Convenção Interamericana Contra a Corrupção em 1996 e os mecanismos de controle em 2005, informantes do Latinobarômetro (2005), de âmbito regional, declararam que acreditavam que mais de $68 \%$ dos funcionários públicos eram corruptos, variando de $41 \%$ no Uruguai a $82 \%$ no Equador.

Relacionada ao assunto de corrupção está a questão da impunidade, que deixa claro às pessoas da região que as elites de seus países não pagam seus impostos, não tratam seus empregados com dignidade, e têm favorecimento no acesso a contratos. A crença de que os poderosos ficam impunes à justa aplicação da lei enfraquece o etos democrático. Isso viola o contrato social. Uma pesquisa de opinião realizada há menos de dois anos verificou que $66 \%$ dos latinoamericanos declararam que eles tinham pouca ou nenhuma confiança no sistema judicial.

Fortalecer o poder da lei deve ser uma preocupação de alta prioridade de alguém que tenha interesse na estabilidade política, em políticas de reforma econômica e no fortalecimento da coesão social. É também importante resolver as causas fundamentais de conflito em muitos dos países da região. Na Colômbia, é absolutamente essencial, se o país coloca aí o espectro do para-militarismo, que o Ministro da Justiça e a suprema corte possam levar a cabo investigações e processos do escândalo para-político. No Haiti, é importante saber se o país, extremamente pobre, pode começar a operar sob o poder da lei. $\mathrm{Na}$ Guatemala, isso é essencial para determinar se forças de segurança que continuam conduzindo execuções extrajudiciais serão processadas. Em cada um desses países, há a necessidade de uma política mais competente, de um judiciário imparcial e de uma sociedade civil que espere e exija a justa aplicação da lei, bem como garantias para os cidadãos, e energia para assegurar acesso ao sistema de justiça para os pobres, indígenas e as minorias étnicas.

Os desafios que eu tenho descrito são reais, mas não novos. Muitos já os identificaram no passado. A questão, como Carlos Fuentes 
disse, é "como chegar lá". Nós temos que engendrar melhores soluções políticas para encontrar aquele caminho.

Cerca de 60 anos atrás, um grande poeta latino-americano, Pablo Neruda, escreveu uma ode a Bolívar. Ele concluiu com estas palavras, "eu conheci Bolívar em uma larga manhã em Madri, na Boca do Quinto Regimento. Pai, Ihe disse, és ou não és quem era? E olhando o Quartel da Montanha, disse: desperto a cada cem anos quando desperta o povo."

Nosso desafio é encontrar maneiras da mobilizar politicamente grupos populares como uma força positiva e não-violenta para produzir as reformas que fortaleçam a democracia, expandam o crescimento econômico e promovam maior igualdade. Nesse momento, devemos realmente buscar ir além do Consenso de Washington.

Mark L. Schneider is senior vice-president, International Crisis Group. E-mail: mschneider@crisisgroup.org. 